\section{DNA from an extinct plant}

SIR - The Dominican amber deposits have yielded a wealth of information about organisms living 25-40 million years ago in Hispaniola ${ }^{\mathrm{T}}$. We now report the extraction, amplification and sequencing of the chloroplast gene $r b c L$ from a leaf of the extinct tree, Hymenaea protera Poinar (Fabaceae: Caesalpinioideae) (see ref. 2) in Dominican amber. Amber containing the leaf of $H$. protera (Fig. 1) originated from La Toca mine, between Santiago and Puerto Plata in the Cordillera Septentrional of the Dominican Republic.

Present knowledge about species diversity and distribution of the genus Hymenaea has been largely based on morphological characters. Lee and Langenheim $^{3}$ divided the genus Hymenaea into a primitive Trachylobium section with $H$. verrucosa and $H$. oblongifolia, and a more advanced Hymenaea section with $H$. courbaril, concluding that an extinct ancestral stock gave rise to $H$. verrucosa and $H$. oblongifolia, with the latter giving rise to $H$. courbaril. We tested this hypothesis by using $r b c L$ sequences from both extinct and extant taxa. We extracted DNA from leaf fragments of $H$. protera from the amber piece using previously described methods $^{4,5}$ and from pieces of surfacesterilized leaves from herbarium specimens of $H$. verrucosa, $H$. oblongifolia and $H$. courbaril (supplied by $\mathrm{J}$. Strother). Using primers complementary to conserved regions of the ribulose bisphosphate decarboxylase $r b c L$ gene, we amplified a 346-base-pair fragment flanked by the primers Z1 and Z346R, using polymerase chain reaction (PCR).

We sequenced PCR products by the dideoxy termination method and used all resulting sequences from Hymenaea spp. as queries in searches of the nucleicacid sequences database using the MacVector 3.5 (IBI Kodak) DNA analysis program. We obtained high similarity



FIG. 1 Leaf of $H$. protera in amber from La Toca mine. The amber has been dated as $35-40$ million years old. scores with all $r b c L$ sequences present in the database, with the highest scores corresponding to those sequences from taxa in the family Fabaceae. Even higher scores were obtained by comparing the extant Hymenaea spp. with each other and with the extinct $H$. protera. Thus we conclude that the amplified product resulting from extracted $H$. protera was indeed from the $r b c L$ gene.

We aligned sequences from Hymenaea and $H$. oblongifolia than between $H$. protera and $H$. courbaril. This suggests that $H$. courbaril may be as old a taxon as members of the primitive section Trachylobium, but for some reason it has diversified much more rapidly than $H$. oblongifolia, which is restricted to the evergreen forest ecosystem of South America, and has remained fairly static over the same period.

This study essentially doubles the age of DNA that can be recovered and sequenced from extinct plants ${ }^{8}$. It shows that amber preserves the DNA not only


FIG. 2 Phylogenetic trees of extinct and extant taxa based on sequences of the $r b c L$ gene, obtained by neighbour joining (a) and maximum parsimony $(b)$. Numbers at the nodes of branches represent bootstrap confidence values obtained from 2,000 replications. Length of maximum parsimony tree (branch and bound method) is 176 . Consistency index $(\mathrm{Cl})=0.807 . \mathrm{Cl}$, excluding uninformative sites, $=0.688$. We corrected for transitions and transversions, resulting in identical tree topologies and nearly identical bootstrap confidence values. Sequences other than those from Hymenaea were extracted from the GenBank nucleic-acid database. The following taxa and accession numbers were used: Algae, used as the outgroup (Chlorella-like) Number M74441; palm (Serenoa repens) accession number M81815; petunia (Petunia hybrida) accession number X04976; tobacco (Nicotinia otophora) accession number M16867; rice (Oryza sativa) accession number X04789; and pea (Pisum sativum) accession number X03853.

spp. and other taxa to investigate phylogenetic analyses and to establish possible evolutionary relationships between extinct and extant Hymenaea spp. The aligned sequences were analysed by two methods, maximum parsimony (PAUP3; D. Swofford) and neighbour joining using the programs NJBOOT2 and Treeview (K. Tamura, Pennsylvania State University). Statistical confidence in the topologies was assessed using the bootstrap method, with 2,000 replications.

Our results corroborate earlier conclusions based on floral and vegetative morphology, indicating a sister-group relationship between the extinct Antillean species $H$. protera and the extant East African species, $H$. verrucosa? This is supported by the high bootstrap confidence values ( $84 \%$ ) obtained (Fig. 2), indicating a true phylogenetic relationship between these two species. At the same time, the data suggest that $H$. protera is more closely related to $H$. courbaril than to $H$. oblongifolia (based on distance calculations). Since $H$. courbaril is placed in the more advanced section of Hymenaea, we expected to see a closer relationship between $H$. protera of invertebrates, but also the remains of angiosperms. Lavin and Luckow ${ }^{9}$ have recently concluded that there is a closer relationship between the flora of Africa and North and central America than there is between Africa and South America, which agrees with the conclusions from our new data on Hymenaea. Hendrik N. Poinar

Raul J. Cano

Biological Sciences Department,

California Polytechnic State University,

San Luis Obispo, California 93407, USA

George 0. Poinar Jr

Department of Entomological Sciences,

University of California,

Berkeley, California 94720, USA

\footnotetext{
1. Poinar. G. 0. Jr Life in Amber (Stanford University Press, 1992)

2. Poinar. G. O. Jr Experientia 47. 1075-1079 (1991) 3. Lee, Y.-T. \& Langenheim, J. Univ. Calif. Publ. Bot. 69. $1-36(1975)$

4. Cano, R. J.. Poinar, H. N. Roubik, D. W. \& Poinar, G. O. Jr Med. Sci. Res. 20, 249-251 (1992).

5. Cano, R. J., Poinar, H. N. \& Poinar, G. O. Jr Med. Sci. Res. 20.619-623 (1992)

6. Saitov. N. \& Nei, M. Molec. biol. Evol. 4, 406-409 (1988).

7. Hueber, F. M. \& Langenheim, J. Geotimes 31, 8-19 (1986).

8 Golenberg. E. M. et al. Nature 344, 656-658 (1990)

9. Lavin, M. \& Luckow, M. Am. J. Bot. 80, 1-14 (1993).
} 